ISSN: 2238-8052

\title{
MOVIMENTOS SOCIOTERRITORIAIS DE LUTA POR HABITAÇÃO NAS PEQUENAS CIDADES DA BAHIA: O QUE INDICA A SUA (IN)EXISTÊNCIA?
}

\author{
MOVIMIENTOS SOCIOTERRITORIALES DE LUCHA POR HABITACIÓN EN LAS PEQUEÑAS \\ CIUDADES DE BAHÍA: QUÉ INDICA SU (IN)EXISTENCIA?
}

Oriana ARAUJO ${ }^{1}$

Artigo recebido em 22/04/2019 e aceito em 20/07/2019

Palavras-chave:

Movimentos sociais,

Mobilizações sociais,

Sem-teto,

Moradia.
Território do sisal,

\section{R E S U M O}

O texto identifica e discute a presença (ou ausência) de movimentos sociais de luta por habitação popular ou de mobilizações sociais relacionadas à moradia nas pequenas cidades da Bahia, nos vinte municípios do território de identidade do sisal. Há conflitos relacionados à moradia em nove dos vinte municípios do território do sisal, mas não foram encontrados movimentos sociais de luta por habitação no território do sisal e sim importantes mobilizações sociais em Itiúba, São Domingos, Valente, Retirolândia, Conceição do Coité, Quijingue e Barrocas, bem como ocupações diretas em Santaluz e Araci, que estão relacionadas ao questionamento da propriedade privada e da busca pelo valor de uso do solo urbano e do atendimento ao direito à moradia, o que demonstra que a população das pequenas cidades do semiárido baiano não é inerte, que outras forças estão sendo engendradas, há insurgências importantes, há articulações espontâneas e muito corajosas que podem gestar outros imaginários e novas ordens socioespaciais.

\section{A B S T R A C T}

Keywords:

Movimientos sociales, Movilizaciones

sociales,

Sin techo,

Territorio del sisal, Vivienda.
El texto identifica y discute la presencia (o ausencia) de movimientos sociales de lucha por vivienda popular o de movilizaciones sociales relacionadas a la vivienda en las pequeñas ciudades de Bahía, en los veinte municipios del territorio de identidad del sisal. Hay conflictos relacionados con la vivienda en nueve de los veinte municipios del territorio del sisal, pero no se han encontrado movimientos sociales de lucha por vivienda en el territorio del sisal y sí importantes movilizaciones sociales en Itiúba, São Domingos, Valente, Barrocas, así como ocupaciones directas en Santaluz y Araci, que están relacionadas al cuestionamiento de la propiedad privada y de la búsqueda por el valor de uso del suelo urbano y de la atención al derecho a la vivienda, lo que demuestra que la población de las pequeñas ciudades del semiárido bahiano no es inerte, que otras fuerzas están siendo engendradas, hay insurgencias importantes, hay articulaciones espontáneas y muy valientes que pueden gestar otros imaginarios y nuevas órdenes socioespaciales.

\section{INTRODUÇÃO: CIDADES PEQUENAS E LUTA POR HABITAÇÃO POPULAR NA BAHIA}

"É um equívoco pensar que problemas urbanos podem ser resolvidos sem solução da problemática social. É esta que comanda e não o contrário" (Milton Santos, 2009, p. 125)

\footnotetext{
1 Doutora em Geografia (Universidade de Santiago de Compostela). Professora do curso de Geografia (Universidade Estadual de Feira de Santana). E-mail: orianageo@gmail.com.
} 
As cidades pequenas e/ou pequenos municípios são excelentes recortes de análise para os estudos geográficos que se relacionem a questões de ordem política, devido ao fato de que a aparente 'maresia' e repetição nas dinâmicas locais dos pequenos municípios baianos, podem ser reveladores dos pactos tácitos entre suas elites hegemônicas (SOUSA SANTOS, 2010) para a manutenção do status quo, considerando que, quando há boas práticas de gestão e politização da sociedade civil, mesmo pequenos municípios potencializam suas perspectivas econômicas, culturais, políticas, sociais, perceptíveis na organização espacial e nos processos espaciais, como constatado por Santos (2010) ao investigar as práticas relacionadas à Associação de Pequenos Agricultores do Estado da Bahia (APAEB) de Valente-BA.

Por essa razão, cabe investigar mais atentamente os processos de 'pseudoinércia' especialmente nas pequenas cidades/ municípios, a exemplo das questões territoriais urbanas, relacionadas a dimensões como o poder, o cotidiano, a politização da sociedade e a contestação das contradições e desigualdades do espaço urbano produzido, englobando diversos agentes sociais.

Acolhe-se a concepção de Fonseca (2003) de que os pequenos e médios municípios possuem forte potencial endógeno capaz de promover transformações importantes, tanto no que concerne ao engajamento da população, quanto em termos territoriais, culturais, sociais e históricos, de modo que não são “(...) recipientes amorfos e submissos a tudo que vem de fora” (FONSECA, 2003, p. 20).

Esse texto objetiva identificar e discutir a presença (ou ausência) e atuação de movimentos sociais de luta por habitação popular ou de mobilizações sociais que originem conflitos sociais por habitação nas pequenas cidades da Bahia, adotando como amostra representativa os vinte municípios do território de identidade do sisal, a partir de pesquisa exploratória.

Considerou-se, a priori, a hipótese de que os movimentos de luta por habitação popular nas pequenas cidades da Bahia inexistem nesses municípios, onde nada ocorre nesse sentido. Entretanto, no caso estudado, tal hipótese fora apenas parcialmente comprovada - haja vista a não identificação de movimentos sociais -, mas a ideia de que nos pequenos municípios nada acontece de cunho contestatório, encontra-se completamente refutada e passou-se a investigar formas espontâneas de contestação popular, mais bem caracterizadas como mobilizações sociais, que resultam em conflitos urbanos mais imediatistas, porém de suma importância para a produção do espaço urbano.

Santos (2011, p. 146) defende que "A localização dos conflitos com todos os atributos a eles associados nos permite compreender a complexidade das múltiplas hierarquias que conformam a sociedade e seu espaço". Concordando-se com o autor, infere-se que a constatação da ocorrência de mobilizações sociais de luta por moradia, com ações as mais variadas em alguns dos pequenos municípios da Bahia, indica a existência de contestações públicas das estruturas sociais que promovem a desigualdade e a privação de direitos constitucionais dos quais resultam processos variados de exclusão social, ainda que nem sempre revelados pelas paisagens urbanas dos pequenos municípios. 
A existência de conflitos urbanos de luta por habitação é reveladora de um processo de tomada de consciência dos problemas, do reconhecimento da igualdade, do saber que conduz à identificação da exclusão e, mais ainda, da capacidade e força de organização, questionamento e luta, que atesta o despertar dos segregados e excluídos, conforme argumentam, dentre outros autores, Lacoste (2006 [1977]) e Izaguirre (2003). Nesse sentido, coaduna-se com Melucci (1994), citado por Bonfim (2002) ao indicar que a ação coletiva é um resultado e não um ponto de partida.

\section{PROCEDIMENTOS METODOLÓGICOS}

Esse texto resulta de uma pesquisa exploratória (GIL, 2011), na qual buscou-se identificar a existência de movimentos sociais de luta por habitação popular ou a existência de conflitos urbanos resultantes de ações coletivas organizadas independentemente de sua duração, em pequenas cidades da Bahia, desde o ano 2000 ao ano corrente (início do século XXI).

Com esse intuito, realizou-se um levantamento bibliográfico do qual resultou o referencial teórico brevemente debatido, de conceitos como movimentos sociais, movimentos socioterritoriais e Sem-teto.

Foram utilizados dados do censo de 2010 para caracterizar o universo das pequenas cidades na Bahia. Constatada sua predominância quantitativa, mas sua desvantagem absoluta e percentual no que tange ao contingente populacional em relação às médias e grandes cidades, conforme já verificado por outros pesquisadores como Silva e Rocha (2003), além de Lopes (2010) - que assumiu o critério da ONU de 20.000 habitantes para considerar pequenas as cidades baianas com esse contingente, enquanto as cidades de até 10.000 habitantes foram consideradas muito pequenas - e J. Santos (2009) que considerou médias as cidades baianas cujo contingente populacional situe-se entre 50.000 a 500.000 habitantes.

Optou-se por investigar uma parte representativa desse universo: os vinte municípios do território do sisal, por conta da dificuldade de localização de dados sistematizados sobre essa temática nos 417 municípios da Bahia, especialmente sobre os pequenos.

Uma razão para a escolha do território do sisal diz respeito ao fato de se encontrar completamente no semiárido baiano, onde historicamente predominaram formas desiguais de apropriação dos bens materiais e imateriais necessários à vida (mesmo os mínimos), de modo que os índices de pobreza ainda são muito altos (SANTOS, SILVA e ARAUJO, 2010). Outra questão importante diz respeito às diferentes estratégias de reprodução no poder pelas elites endógenas e à condução política dos municípios (com raras exceções) calcadas no assistencialismo e cooptação. 
Paradoxalmente, no território do sisal há forte organização popular na composição de associações (SANTOS, SILVA e COELHO NETO, 2011) e sindicatos constituindo-se num território com fortes movimentos socioespaciais, de acordo com a perspectiva de Fernandes $(2000 ; 2005)$.

Conforme discutem Santos, Coelho Neto e Silva (2015), as mudanças são processos lentos e, considerando-se que a própria invenção de uma região do sisal calcada na hereditariedade e tradição política, na manutenção das desigualdades sociais e no conformismo da população, vem sendo questionada, desafiada a mudar para a concepção de território de identidade do sisal ${ }^{2}$, denotaria a insurgência de nova concepção, na qual os movimentos sociais devem atuar, o que pode representar a esperança de que o futuro pode vir a ser mais justo.

Firme-Vieira (2011), contrariamente a essa perspectiva e, muito menos otimista com a aparente 'mudança' nas políticas públicas a partir do governo Lula, investigou a implantação da política de desenvolvimento territorial rural no Rio de Janeiro e seus desdobramentos para os grupos subalternos envolvidos, concluindo que se exerceu mecanismos de controle sutis em que a participação dos grupos subalternos esteve mais voltada para a sua incorporação na política estatal pretendida do que para a montagem de uma política que efetivamente os atendesse.

Dentre as razões que justificam essa escolha está ainda o fato do território do sisal ter sido foco de algumas investigações realizadas por essa autora e consistir também em seu espaço de vivência, num dos seus pequenos municípios, o que a obriga a redobrar a atenção nas análises, a fim de evitar idiossincrasias.

Considerando-se que aproximadamente $70 \%$ do espaço baiano situa-se no semiárido e que há muitas similaridades sociais entre esses municípios, julga-se que o território do sisal representa razoavelmente esse universo do Estado que é pouco investigado em suas especificidades.

Assumiu-se a amostragem por acessibilidade ou por conveniência (GIL, 2011), como suficiente para o objetivo aqui pretendido, de modo que toda a pesquisa fora realizada com dados secundários.

Foram realizadas buscas na internet utilizando as seguintes palavras/ marcadores: 'sem-teto, Bahia, ocupação, invasão, nome de cada um dos municípios do território do sisal' (marcadores combinados ou excluídos). De modo complementar consultou-se as páginas oficiais dos movimentos sociais de luta por habitação da Bahia na internet, bem como suas páginas nas redes socais (quando existem).

A pesquisa nos sites dos maiores jornais diários on-line da Bahia não apresentou bons resultados. A notícia sobre os pequenos municípios parece ser mesmo interesse de sites e jornais menores, mais locais ou regionais. Devido à relevância na divulgação de notícias sobre os municípios

\footnotetext{
2 É pertinente considerar a reflexão realizada pelo geógrafo Carlos Walter Porto-Gonçalves (em conferência no 2o Seminário do GEOMOV-UEFS, 2012), de que a própria nomenclatura 'território de identidade do sisal' é muito frágil, já que, enquanto planta, cultivo agrícola, o sisal não produz território: quem produz território são as pessoas, os agentes sociais, de modo que o topônimo um pouco menos incômodo poderia ser Território [do povo] sisaleiro.
} 
pesquisados, efetivou-se uma refinação na busca pelo marcador 'sem teto' no site 'Calila Notícias', de Conceição do Coité, que apresentou bons resultados.

As imagens relacionadas aos termos pesquisados também foram verificadas e, em muitos casos, a partir delas descobriu-se blogs e sites que noticiaram algum ato relacionado aos termos da busca (RUBEM, 2015; JORGE QUIXABEIRA.COM; CORREIA (2015); CARVALHO 2012; CALILA NOTÍCIAS, 2015; ASSIS, 2011, 2012, 2013).

O levantamento de dados realizado, baseado em informações disponíveis na internet, não representa o universo investigado na íntegra, mas com parcimônia - tendo em vista uma série de questões que vão desde o 'desinteresse' das mídias locais e regionais em visibilizar ações de Sem-teto, até a inexistência de sites de notícias em décadas anteriores nesses municípios, bem como da omissão dos marcadores utilizados na pesquisa -, entretanto, o teste do procedimento indicou bons resultados e, por essa razão foi aplicado.

Os dados encontrados foram organizados em um quadro síntese e confrontados com a população urbana de cada cidade. Posteriormente, organizou-se a cartografia da ação social relacionada à luta por moradia no território do sisal.

\section{MOVIMENTOS SOCIOTERRITORIAIS DE LUTA POR HABITAÇÃO: BREVE CONSIDERAÇÃO TEÓRICA}

Um movimento social não corresponde a toda e qualquer 'ação social', 'manifestação social' ou 'ações coletivas', por causa do caráter de instantaneidade e imediatismo que tais fenômenos podem adquirir.

As expectativas apontadas por Frank e Fuentes (1989) de que os movimentos sociais são cíclicos, devido às mudanças conjunturais (ciclos políticos, econômicos e ideológicos) que os produziram, de modo que podem desaparecer, impõem a necessária reflexão sobre a abordagem dos movimentos sociais. Na perspectiva de Gohn (2010):

Movimentos sociais são ações sociopolíticas construídas por atores sociais coletivos pertencentes a diferentes classes e camadas sociais, articulados em certos cenários da conjuntura socioeconômica e política de um país, criando um campo político de força social na sociedade civil. As ações se estruturam a partir de repertórios criados sobre temas e problemas em conflitos, litígios e disputas vivenciados pelo grupo social. As ações desenvolvem um processo social e político-cultural que cria uma identidade coletiva para o movimento, a partir dos interesses em comum. (GOHN, 2010, p. 251).

Embora elementos como a formalidade, organização e estabilidade, bem como a polêmica questão da durabilidade ou longevidade do movimento social, além das questões referentes ao tipo de pauta da luta e sua 'novidade' suscitem importantes discussões entre os diversos pesquisadores da área, as discussões tendem a apontar para a ideia de que os movimentos sociais advêm de um 
processo político, social e cultural a partir dos interesses comuns e sua atuação não se condiciona a apenas uma ação ou mobilização social que se esgota quando o objetivo é atingido.

Para Mellucci (1989, p. 57), um movimento social é “[...] uma forma de ação coletiva (a) baseada na solidariedade, (b) desenvolvendo um conflito, (c) rompendo os limites do sistema em que ocorre a ação". De modo análogo, Touraine (2006) reitera que o uso da categoria movimentos sociais deve ser reservado ao conjunto dos fenômenos que foram assim nomeados numa longa tradição histórica, correspondentes "[...] a uma ação coletiva que coloca em causa um modo de dominação social generalizada" (TOURAINE, 2006, p. 18).

Para o autor, a oposição à dominação é uma dimensão fundamental na definição do movimento social: "[...] só há movimento social se a ação coletiva - também ela com um impacto maior do que a defesa de interesses particulares em um setor específico da vida social - se opuser a tal dominação." (TOURAINE, 2006, p. 19).

$\mathrm{Na}$ distinção elaborada por Montaño e Duriguetto (2011) entre movimentos sociais e mobilizações sociais, estas assemelham-se aos ativismos sociais definidos por Souza (2009), uma vez que indicam o seguinte:

[...] um "movimento social" caracteriza uma organização, com relativo grau de formalidade e de estabilidade, que não se reduz a uma dada atividade ou mobilização. Uma "mobilização social" remete a uma atividade, que se esgota em si mesma quando concluída. (MONTAÑO e DURIGUETTO, 2011, p. 264).

Nesse sentido, embora as mobilizações sociais de luta por habitação social nas pequenas cidades da Bahia, em sua maioria não resultem da atuação deliberada de um movimento social constituído para tal fim, os marcos que estabelecem nesses espaços urbanos, a contestação da ordem vigente, o senso de cidadania e igualdade que ensejam, indicam que as mobilizações sociais por moradia nos pequenos municípios devem ser analisadas.

Das contribuições de Porto-Gonçalves (1998; 2006; 2010), se depreende que o próprio movimento social já implica em mudança, capaz de inscrever na terra uma escrita própria, uma outra forma de grafar o espaço, uma geograficidade do social, a partir do surgimento de novos protagonistas, de novos campos de força política, de poder, de modo a produzir práticas emancipatórias.

No caso dos movimentos de luta por terra, por território urbano ou rural, o território se constitui num trunfo para os movimentos, uma vez que sua luta não apenas se territorializa, como também ocorre no território e por território, resultando além das territorialidades visíveis também em espacialidades que ficam marcadas na memória coletiva ativando discussões sobre outras possibilidades políticas de uso e gestão do espaço, de modo que os movimentos socioterritoriais são sempre socioespaciais, mas os movimentos socioespaciais não são sempre socioterritoriais Fernandes (2000; 2005) e Martin (1997). 
Adota-se nessa explanação perspectiva semelhante às de Mellucci (1989), Souza (2009), Touraine (2006), Montaño e Duriguetto (2011), de que nem toda prática política de ocupação de um imóvel ou terreno urbano indica a existência de um movimento social de luta por habitação popular, porque as ocupações de terrenos e mobilizações para a consolidação de moradias podem advir da organização efêmera de cidadãos unidos apenas para resolver o seu problema imediato de falta de moradia, constituindo uma ação coletiva ou mobilização social importante, cuja marca territorial está presente no espaço geográfico onde territorializaram-se ou na memória de seus habitantes, demonstrando que espacialidades importantes foram constituídas, conforme enuncia Fernandes (2005).

Ademais, nem sempre os ocupantes identificam-se como Sem-teto, por razões variadas, mas essencialmente devido ao imaginário pejorativo difundido sobre os Sem-teto.

A atuação de um movimento social não cessa imediatamente após a conquista do objeto de luta ou uma ação. Nesse sentido, as dimensões simbólico-culturais e políticas que servem de impeditivos importantes para a sua constituição nos pequenos municípios, aliadas às próprias dimensões espaciais dos problemas urbanos nessas localidades, que ocorrem de modo menos acentuado do que nos médios e grandes municípios, dificultam a organização de movimentos sociais de luta por habitação.

No Estado da Bahia, de modo geral, quando ocorrem ocupações nos municípios pequenos estas costumam ser resultados de ações coletivas ou manifestações sociais espontâneas e efêmeras, que constituem-se em importantes indicadores do protagonismo social (PORTO-GONÇALVES, 2005, citado por SANTOS, 2011) dos mais pobres e de demonstração da força popular no questionamento das formas privadas de acesso à terra urbana e à moradia, que possuem importantes desdobramentos territoriais e espaciais - mesmo quando o objeto principal da luta, que é o terreno ou a moradia, não é conquistado -; ou ainda, conforme constatou Araujo Silva (2018) podem estar vinculadas a um movimento estadual que organizou a ocupação e a luta no pequeno e mesmo no médio município, como ocorre com o Movimento dos Trabalhadores Sem-Teto da Bahia (MSTB).

Por essa razão, ainda que não seja possível classificar muito do que ocorre nos pequenos municípios baianos como movimentos sociais de luta por habitação, o estudo das ações espontâneas dos seus cidadãos ou das mobilizações/ ativismos sociais e seu processo de organização e luta devem ser incorporados na análise da produção do espaço urbano, por indicarem que novos campos de força política estão se estabelecendo na busca do valor de uso do solo urbano, contrários à mera especulação imobiliária e ao uso do solo urbano apenas como mercadoria, a partir de seu valor de troca ou comercial, conforme asseguram Santos (2011) e Maricato (2011), resultando na produção da cidade do capital ou cidade do apartheid, como indicado por Boulos (2015). Tal assertiva é reiterada pelo questionamento afirmativo de um ocupante de terreno na cidade de Santaluz - Bahia, em 2013, 
ao falar sobre a 'onda de protestos' em Santa Luz: “[...] o Brasil acordou, porque Santaluz não acorda?” (ASSIS, 2013).

\section{QUEM PODE SER CONSIDERADO SEM-TETO? QUEM QUER SER SEM-TETO NA CIDADE PEQUENA?}

Os Sem-Teto são a expressão mais evidente da extrema e proposital segregação e fragmentação do tecido sócioespacial das cidades (SOUZA, 2006), resultante do modelo capitalista e, no caso latinoamericano, das mazelas herdadas do período escravista colonial: a multiplicação dos 'sem propriedade', que conforme indica Menegat (2005), é um termo que mantém atrelada a identificação das pessoas com a exclusão do acesso à terra rural e urbana, de modo que as próprias áreas de favelas e ocupações nas grandes cidades já não comportam mais a imensidão de pessoas sem propriedade: a própria periferia já está ou é um limite.

Coaduna-se com Pedón (2013, p. 199) ao indicar que: “A preposição sem designa ausência de lugar, sugere o sentido de privação, da falta e da exclusão. No caso dos sem-teto, a denominação não faz referência a casa, mas sim ao território que lhe permite ser soberano sobre um espaço, sem o qual não passa de um nômade".

O 'morador de rua' é a forma mais evidente de 'Sem-teto': seres humanos excluídos das próprias periferias das cidades, das favelas e das áreas irregularmente ocupadas, que tentam morar nas ruas, estando expostos a diversas mazelas, que vão desde as intempéries naturais à violência social. Nas palavras de Guilherme Boulos 3 :

É preciso, primeiramente, deixar de lado a visão equivocada de que sem-teto são aqueles que moram na rua, em situação de extrema miséria e mendicância. Esse grupo é aquele que chegou ao limite da degradação causada pela falta de moradia, pelo desemprego e outros males do sistema capitalista. A maioria dos sem-teto não está em situação de rua e trabalha, ainda que muitas vezes na informalidade e sem direitos assegurados. (BOULOS, 2015, p. 31).

A questão é muito mais complexa como demonstra a definição elaborada pelo referido autor:

(...) os sem-teto são todos aqueles que são afetados pelo problema da moradia, seja pela falta dela ou por tê-la nas condições mais precárias. São aqueles trabalhadores a quem o capitalismo atacou de modo brutal, com suas armas mais afiadas: desemprego, baixos salários, trabalho informal, superexploração. (BOULOS, 2015, P. 89-90).

Claro está que essa discussão não trata dos desejos de escolher 'não morar' em lugar nenhum, como fazem alguns poucos ricos - que optam por viajar pelo mundo de hotel em hotel, ['cidadãos globais', na plenitude da prática de sua multiterritorialidade? (HAESBAERT, 2010)] -, ou daqueles que por questões religiosas e/ou filosóficas resolvem viver de albergue em albergue.

${ }^{3}$ Dirigente do Movimento dos Trabalhadores Sem-Teto. Filósofo (USP). 
Sem-teto são pessoas que, devido a contingências econômicas relacionadas ao baixo assalariamento, desemprego, informalidade no trabalho, sofrem extremas dificuldades econômicas que lhes impossibilita o acesso ao custoso mercado de moradias, de modo que submetem-se a diversos arranjos que vão desde aluguéis demasiadamente onerosos às habitações insalubres, à coabitação forçada, ao improviso de moradia de 'papelão, materiais variados e plástico', aos barracos eternamente inacabados, até os viadutos, albergues e ruas, sobre-vivendo com o que lhes possibilita a sua luta cotidiana. Podem filiar-se ou não a movimentos de luta por habitação (ARAUJO, 2017).

Segundo a Fundação João Pinheiro (2015, p. 08), em 2013 havia na Bahia um déficit habitacional ${ }^{4}$ de 417.026 unidades habitacionais, do qual 307.344 unidades em déficit são urbanas.

A exclusão social ocorre também nas pequenas cidades; contudo, ante seu menor impacto territorial e menor visibilização, tem-se a errônea sensação de que todos vivem adequadamente nas pequenas cidades, que pode ser facilmente refutada em trabalhos de campo nas áreas mais pobres das pequenas cidades.

Ademais, estudos mais específicos como a pesquisa realizada por Denaldi, Camaru e Gonçalves (2014), que utilizou dados do sistema de informação de atenção básica organizado pelos agentes comunitários de saúde - haja vista a existência de formulário que informa as características construtivas, condição de moradia, acesso à infraestrutura e serviços urbanos -, a fim de identificarem a precariedade habitacional, demonstrou claramente que no município de Água Fria, na Bahia (Território do Portal do Sertão), a exclusão social se traduz na precariedade das condições de moradia às quais se submetem a população de menor renda.

A intimidade cotidiana estabelecida nas pequenas cidades, a proxemia - no seu sentido de proximidade espacial e proximidade social, nem sempre correlatas (SANTOS, 2011, baseado em Stuart Hall) -, e o controle dos empregos (prefeitura, comerciantes, pequenos empresários) funcionam também como fatores coercitivos eficientes para manter a 'ordem vigente' e o interesse de uma elite aviltante que detém o poder político e a supremacia econômica, 'inventada' junto com a invenção de um nordeste pobre e necessitado, que interessou a essa elite forjar, a fim de manter seus privilégios e poder (ALBUQUERQUE JR., 1999), a partir da criação de um 'mito da necessidade', conforme demonstrado por Castro (1992).

De forma correlata ao que ocorre no quadro regional, pode-se acrescentar outra fábula ou mito sobre a pobreza da pequena cidade: o mito instituído de que "a cidade pequena é pobre porque é pequena e é pequena porque é pobre", como se nada pudesse ser feito a respeito. Atribui-se a essas cidades uma incapacidade administrativa e de inflexão socioeconômica que desconsidera o que de fato

\footnotetext{
${ }^{4}$ Corresponde às necessidades das famílias que estão em situação de habitação precária (domicílios rústicos e improvisados), coabitação familiar, adensamento excessivo e ônus excessivo com pagamento de aluguel, vivendo nos 'limites do habitar', como prefere Gordilho-Souza (2008).
} 
ocorre: interessa aos detentores do poder manter a estagnação econômica, o analfabetismo e a miséria humana que lhes sustenta no poder e garante suas benesses.

A letargia proposital nos pequenos municípios pode ser exemplificada pelos casos de SantaluzBA, em que a prefeitura não ingressou no Programa Minha Casa Minha Vida (ASSIS, 2013) e de Quijingue-BA, cujos vereadores não se moveram para possibilitar o acesso ao PMCV (CORREIA, 2015), fatores motivadores de mobilizações sociais por moradia nesses municípios.

Conforme argumenta Prost (1992, citado por ALMEIDA, 2011), a cidade pequena [como alguns bairros de grandes cidades] é o espaço do convívio mútuo, onde há contato social favorecido pelo ambiente pessoalizado e reconhecido, que tende a ampliar a solidariedade e afetividade. Contudo, baseado em Prado (1995), contrapõe que “(...) se viver em uma cidade pequena é um paraíso porque vários sujeitos se reconhecem, este conhecimento mútuo leva a uma vida infernal em virtude de todos controlarem a vida de todos, dificultando, desse modo, o anonimato.", de modo que há um controle social mais amplo e "(...) possui a fofoca como legitimadora de um sutil poder de regulação e vigilância" (ALMEIDA, 2011, p. 345).

A ausência do anonimato na cidade pequena implica na assunção identitária de pertencer ao grupo excluído - os Sem-teto, por exemplo - e, essa filiação identitária requer um grau de politização, coragem e criticidade elevados, capazes de motivar disposições para a contestação, para a mobilização. Esse fator que deveria ser positivo, devido à potencialização do encontro e da mobilidade espacial mais facilitada que nas grandes cidades, pode acabar gerando uma maior dificuldade de organização e mobilização social especialmente no que diz respeito ao questionamento da 'sagrada' propriedade privada, já que no pequeno município todos sabem 'quem é quem': filho de fulano, casada com beltrano, da família de fulana [com o juízo de valor aí imbuído: está nos Sem-teto? 'invadindo' o que é dos outros?].

Nesse sentido, a cidade pequena remonta à cidade local abordada por Milton Santos (2009), na qual se destacam os 'notáveis' (políticos, médicos, professores, funcionários públicos). Por essa razão, a forma como as ideias são gestadas e difundidas é fundamental e, nas pequenas cidades, a difusão das ideias e ideais das elites locais e suas lógicas vis imperam para a conservação das coisas como estão, mantendo a 'cegueira' com relação aos processos de empobrecimento, haja vista possuírem status social e poder que tornam sua fala 'aceita' pela população.

Contudo, embora na maioria das cidades pequenas da Bahia não sejam encontrados facilmente movimentos sociais de luta pela habitação - de Sem-teto -, encontram-se mobilizações e ações mais ou menos efêmeras ou temporárias, com caráter reivindicatório e formas de atuação diferenciadas, que revelam a existência de uma sociedade que, embrionariamente desperta para os quadros de exclusão social a que estão submetidos, exigindo (ainda timidamente) que o Estado cumpra seus deveres no estabelecimento de políticas públicas que garanta os direitos constitucionais, dentre os quais o direito 
à moradia, reiterado pelo Estatuto das Cidades (BRASIL, 2001), de modo que podem se tornar os espaços de esperança em dias melhores, onde os mais fracos comecem a perceber que juntos são verdadeiramente fortes.

\section{MOBILIZAÇÕES SOCIAIS DE LUTA POR HABITAÇÃO POPULAR EM PEQUENAS CIDADES DA BAHIA: UM BREVE EXAME NOS MUNICÍPIOS DO TERRITÓRIO DO SISAL}

Apesar da grande disparidade entre a quantidade de pequenas cidades e a população residente em relação à população residente nas poucas médias e grandes cidades baianas que é inversamente proporcional, a investigação dos processos de produção do espaço geográfico, das suas contradições inerentes, da diversidade e protagonismos dos agentes sociais pode auxiliar a apontar medidas para o planejamento de políticas públicas que visem o reordenamento territorial e a equidade social, tanto no âmbito local - do município, quanto no âmbito estadual.

A partir dos dados dos censos demográficos e conforme se depreende da figura 01, constata-se que as cidades da Bahia aqui consideradas pequenas - ou aquelas com menos de 20.000 habitantes $^{5}$ correspondem a 354 cidades ou $85 \%$ de um total de 417 cidades e possuem juntas 2.562 .429 habitantes, o que representa $27 \%$ de um total de 9.381 .569 habitantes que vivem em cidades na Bahia. Esse contingente é muito significativo, especialmente ao considerar que no total, os 2.562 .429 hab. das cidades com menos de 20.000 hab. da Bahia, é maior do que a população absoluta de sete estados brasileiros: Sergipe, Mato Grosso do Sul, Tocantins, Amapá, Acre, Roraima e Rondônia (IBGE, 2010)6.

Figura 1. Bahia: Distribuição da população segundo a quantidade de habitantes por classe e número de cidades (valores absolutos e percentuais) - Bahia - 2010

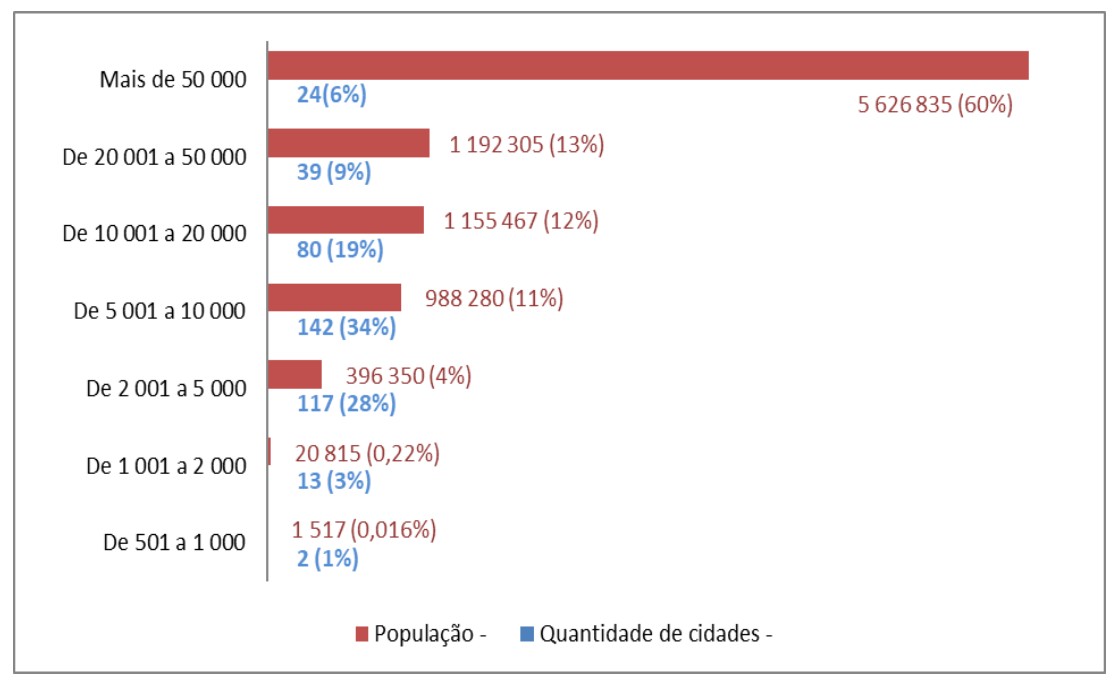

Organização: Oriana Araujo (2016). Fonte: IBGE, Censo Demográfico 1960, 1970, 1980, 1991, 2000 e 2010. Disponível em: http://downloads.ibge.gov.br/downloads_estatisticas.htm.

\footnotetext{
5 Utilizando apenas o parâmetro de população total, conforme a ONU.

${ }^{6}$ http://www.ibge.gov.br/estadosat/index.php.
} 
Conforme salientou-se nos procedimentos metodológicos, não foi possível estudar todo o universo da pequena cidade da Bahia e a luta por habitação e, conforme justificado, optou-se por explorar o território de identidade do sisal. Contudo, é necessário considerar que não se pode atribuir as necessidades habitacionais reais dos baianos apenas aos municípios onde há a atuação de um movimento social de luta por habitação, até porque o Movimento dos Trabalhadores Sem-Teto de Salvador, do qual deriva o Movimento dos Trabalhadores Sem-Teto da Bahia, surgira apenas em 2003.

A cartografia dos conflitos sociais organizados coletivamente, relacionados à questão da moradia no território do sisal, explicitada na figura 02, exemplifica bem o potencial questionador nos municípios pequenos e médios da Bahia, demonstrando o surgimento de novos protagonistas na produção do espaço urbano, considerando-se que

A existência de condições objetivas de miséria, desigualdade, tirania, violência, arbitrariedades por si sós não são suficientes para explicar a existência de um movimento social. É também necessária a existência de sujeitos que tomem iniciativas e, algumas vezes, até mesmo tracem estratégias que passem a se organizar em grupos com ações coletivas e assim se colocar como portadores de novos direitos sociais.

0 protagonista social - aquele que se põe como principal sujeito da ação - tende a desencadear todo um processo de construção de identidades coletivas, de um imaginário social e de uma forma de se organizar e se manifestar. (RANGEL, VILELA E PORTO-GONÇALVES, s/d, p. 03).

A análise comparativa entre os dados encontrados, o contingente populacional e a densidade demográfica municipal, conforme demonstra a figura 03, permite afirmar que o quantitativo populacional absoluto na sede, não explica a existência ou inexistência de mobilizações por habitação, visto que dentre os dez maiores municípios do TS (Território do Sisal) ocorreu algum tipo de conflito em cinco deles (Conceição do Coité, Araci, Santaluz, Valente e Itiuba); nesse sentido, cabe destacar que no maior município que é Serrinha (que também possui a maior densidade demográfica $(116,50$ hab/ $\mathrm{km}^{2}$ ), não foi encontrado nenhum tipo de mobilização social por habitação nesse início de século XXI. Ademais, nos dez menores municípios, com população variando entre menos que 7.000 habitantes até 2.085 habitantes, ocorreu algum tipo de mobilização, essencialmente ligadas ao Programa Minha Casa Minha Vida, em quatro deles (Retirolândia, Barrocas, São Domingos e Quijingue); também nesse caso parece não haver relação direta com a densidade demográfica.

O mapa denota certa proximidade espacial entre os municípios cuja população mobilizou-se de alguma forma na luta por moradia, haja vista a relação de vizinhança entre os municípios de Santaluz, Araci, Retirolândia, São Domingos e Barrocas, nos arredores de Valente e Conceição do Coité (que são importantes centros urbanos no contexto do território do sisal), com maior distanciamento relativo de Quijingue e Itiuba.

Outro destaque nítido no mapa diz respeito ao fato de que os municípios da hinterlândia imediata de Serrinha (com exceção de Conceição do Coité e Biritinga), não apresentaram qualquer tipo 
de mobilização social e conflito relacionados à luta por moradia; além disso, Lamarão, Ichu, Candeal e Biritinga são os municípios com menor contingente populacional na sede do território do sisal.

Figura 2. Conflitos sociais por moradia no Território do Sisal (2000 - 2015)

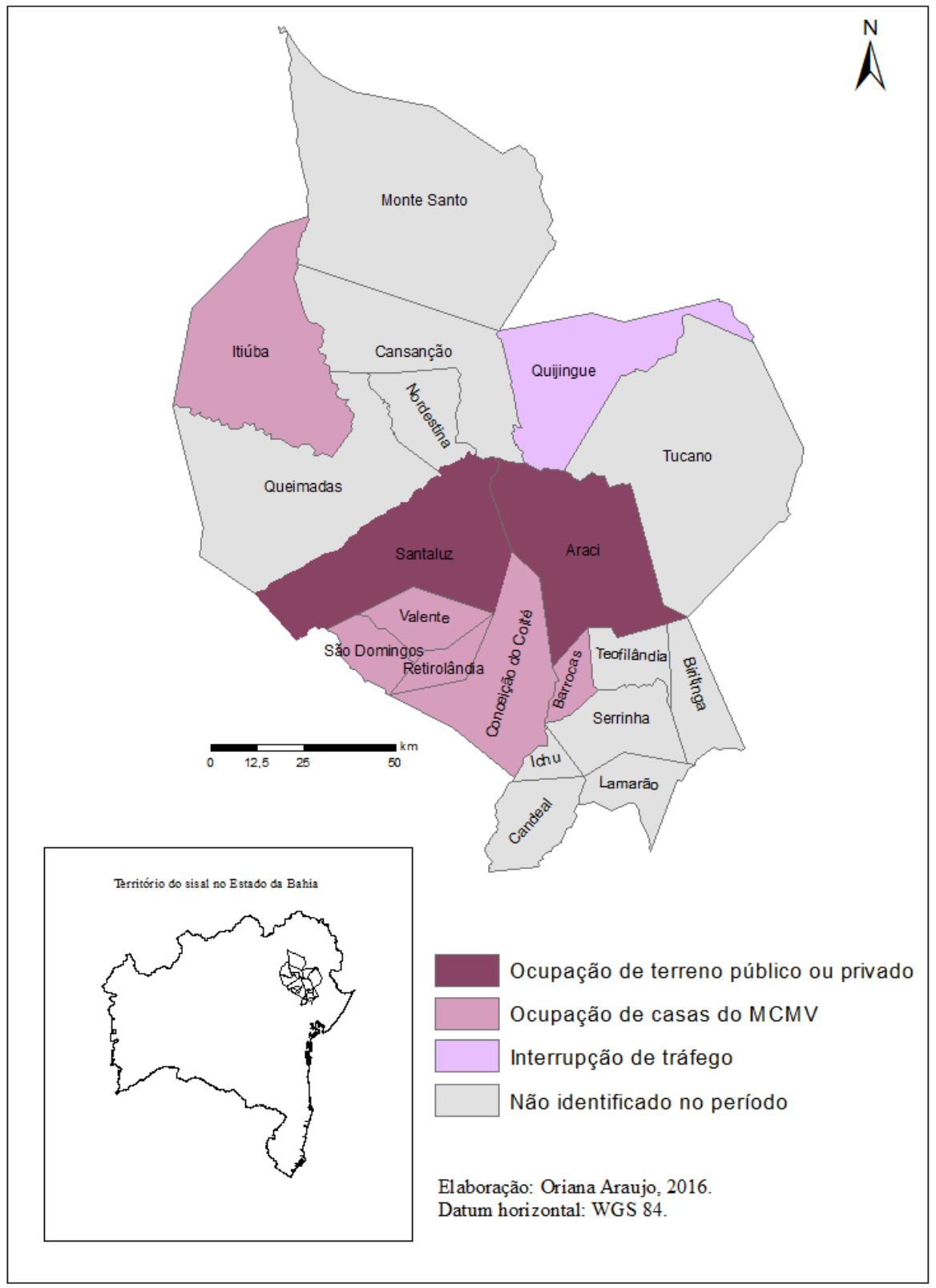

Organização: Oriana Araujo, 2016.

Relacionados à ocupação direta, estratégia que necessita de forte elaboração e senso crítico, estão as manifestações realizadas em Santaluz-BA e em Araci-BA, cuja mobilização social buscou a imediata territorilização do grupo de Sem-teto que almejava a posse do terreno para a construção de moradias. 
Figura 3. População das sedes e densidade demográfica dos municipais do Território do Sisal (2010)

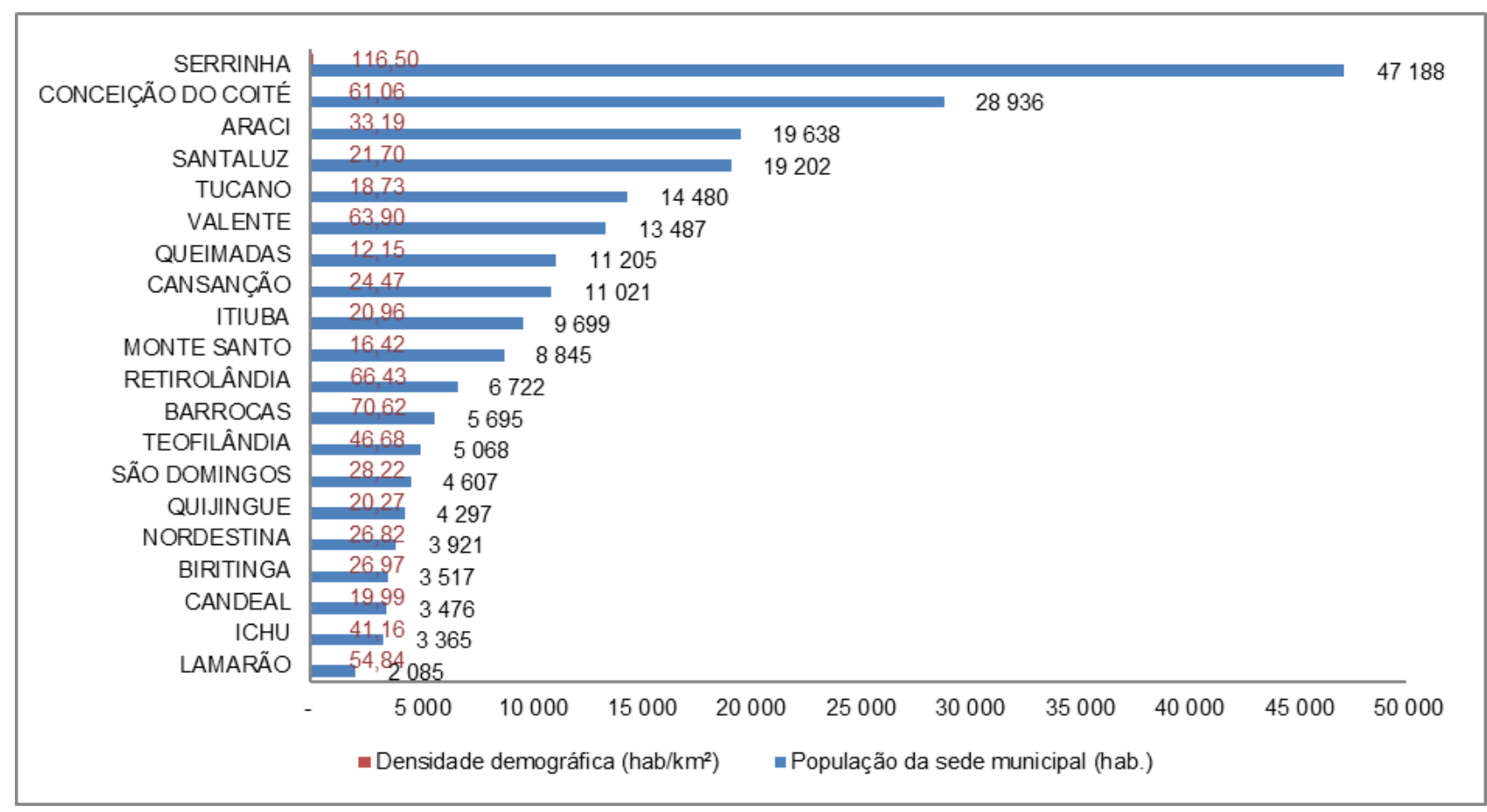

Organização: Oriana Araujo (2016). Fonte: IBGE, Censo Demográfico 1960, 1970, 1980, 1991, 2000 e 2010.

Disponível em: http://downloads.ibge.gov.br/downloads_estatisticas.htm.

O exemplo da ocupação realizada em Santaluz-BA em 2013 é emblemático: A novidade notada na expressão do repórter ao escrever sobre o 'movimento' "que já ganhou até nome - Movimento Morada Livre - MML" (ASSIS, 2013), revela a surpresa ante o questionamento da ordem vigente, muito embora se perceba nas entrelinhas sempre a preocupação com a 'ordem pública', uma vez que se ressalta o caráter pacífico da ocupação e se indica que o efetivo policial do município precisa de reforços.

Elemento também interessante é o fato de alguns ocupantes dizerem que os terrenos não têm dono e que se chegar alguém com o documento desocupam o terreno, denotando o clássico respeito dos grupos não hegemônicos à lei, aos cartórios, memórias dos tempos coloniais, tão bem mantidas, mas incapazes de remeter à função social da terra, ao direito constitucional de moradia, ao Estatuto das Cidades, que garante às prefeituras municipais a cobrança de IPTU progressivo, o dever de realizar o ordenamento do solo urbano e de zelarem para que as terras e imóveis urbanos atendam à função social, conforme argumenta reiteradamente Maricato (2011).

Claro está que os proprietários dos terrenos - um advogado, um ex-prefeito e a própria prefeitura municipal - acionaram os 'dispositivos legais' para lhes garantir os seus direitos e que as forças policiais municipais (que já estavam sendo reforçadas) tomem atitudes para negociarem a saída 'pacífica' dos ocupantes... Tudo isso devidamente apoiado pela maior parte da população que 'se manifestou' em contrário: De 15 comentários que havia sobre a reportagem no site do Calila Notícias (ASSIS, 2013), 7 pessoas eram terminantemente contra a ocupação e os ocupantes, 4 estavam contra o 
gestor atual e protestavam quanto à não participação de Santaluz no Programa Minha Casa, Minha Vida e 4 estavam a favor da manifestação e da ocupação do terreno.

0 refinamento da pesquisa sobre o Movimento Morada Livre - MML, de Santaluz, não apresentou mais nenhum resultado, indicativo de que ou sua criação foi providenciada apenas para nomear uma ocupação específica ou suas ações não têm conseguido atrair a atenção da imprensa, o que reitera o caráter imediatista da ação, de modo a tratar-se de uma manifestação social e não de um movimento social, conforme assumiu-se aqui.

Evidencia-se que tal ação, de per si, indica que há nesse município pessoas capazes de questionar a propriedade privada da terra e seu uso especulativo pelas elites, organizando-se coletivamente para ocupar essas áreas e lutar por outras formas de acesso ao solo urbano e por uma cidade mais acessível, ainda que seja para suprir sua necessidade imediata de moradia.

Em Araci, segundo Carvalho (2012), 30 famílias ocuparam um terreno da prefeitura, mas foram informadas de que seriam terrenos para a construção de equipamentos públicos; não se convenceram - afirmaram que lutariam pelos $5 \mathrm{~m}$ de terrenos que deveriam ser destinados a cada família. A prefeitura, contraditoriamente, sinalizou que poderia negociar a doação, mas que entraria com o pedido de reintegração de posse; um advogado defendeu a ação da polícia que protegeu o patrimônio público (ainda que houvesse denúncia de atuação violenta), indicando que não havia necessidade de ordem judicial, porque a 'invasão' era recente; 0 referido repórter carimbou a notícia e registrou o desejo dos ocupantes:

Mesmo sabendo que não é certo invadir propriedade municipal, os invasores garantem que não vão sair do terreno e promete resistir a uma investida mais forte da polícia ou até mesmo um mandado da justiça, mas esperam da prefeitura uma negociação. "Basta à prefeitura nos dar o terreno, nós construiremos com o nosso suor" - afirmou Edilson. (Carvalho, 2012).

Bomfim (2002) atesta que, após uma ocupação de terreno pertencente a uma empresa, organizada por sem-teto, numa cidade de 200 mil habitantes, no Rio Grande do Sul:

\footnotetext{
"Ninguém na cidade estava isento de opinião. [...] A população da cidade ficou dividida entre os favoráveis (citando o direito a moradia) e os contra (chamando os ocupantes de "delinquentes"). Entre os meios de comunicação, também havia os favoráveis (em defesa do "povo pobre") e os contra ("há pobres que trabalham e não invadem a propriedade alheia"). (BOMFIM, 2002, P. 97-98)
}

Considerando que nos menores municípios, há uma tendência de maior envolvimento da sociedade, emitindo opiniões e juízos de valor, concorda-se com o autor sobre o aumento da possibilidade de envolvimento dos habitantes com a discussão, mas ressalta-se que as opiniões tecidas nos comentários e conversas diárias, na maioria das vezes não são expressadas nos fóruns de discussão difundidos pelos meios de comunicação.

Esse elemento, em municípios muito pequenos, a exemplo dos baianos com cidades com menos de 20.000hab., pode ser um dificultador para a inserção das pessoas em movimentos contestadores da 
propriedade privada, devido à tendência de difusão muito mais eficaz dos discursos hegemônicos do que dos discursos contra-hegemônicos, conforme apontam Modesto (2013) e Sousa Santos (2010), havendo dificuldades para que os mais pobres se reconheçam como iguais e, a partir daí, busquem a igualdade e acesso a seus direitos, conforme salienta Vázquez (2011). É necessário um nível de politização e motivação elevados para a luta, tendo em conta que os adjetivos 'delinquentes, povo pobre, vagabundos, invasores' não são estigmas que se deseje carregar, conforme apontam Tomimura e Muniz (2012).

No contexto do Estado da Bahia essa hipótese parece se verificar porque na quase totalidade dos pequenos municípios encontra-se um número muito grande de movimentos socioespaciais ${ }^{7}$, especialmente as associações comunitárias e sindicatos, voltados especialmente à luta por melhores condições de vida e inserção no mundo do trabalho, do que pela contestação do acesso à terra urbana e rural, mas quase não se encontra movimentos socioterritoriais.

Os movimentos socioespaciais no território sisaleiro são muito importantes e, por vezes, promovem profundas reestruturações socioeconômicas e mesmo espaciais, conforme demonstrado por Santos (2010); contudo, sua atuação não se dá no embate e luta por acesso à moradia e aos meios de produção no espaço rural, considerando-se seu caráter associativista de pequenos produtores, não se constituindo em movimentos socioterritoriais.

Ao discutir a rede urbana atual do território do sisal, Silva (2015) apresentou argumentos que ajudam a compreender os processos de exclusão socioespacial ora em curso:

Outro aspecto a destacar, e que contribui para entendermos o porquê de as pequenas cidades não crescerem significativamente, mesmo com a retomada do crescimento da cadeia produtiva do sisal após a reestruturação ocorrida nos anos de 1990, é a questão político-administrativa. Ou seja, a intensa concentração da renda nas mãos de uma pequena "elite do sisal", aliada à gradativa ampliação da exploração dos trabalhadores relegados à miséria e ao analfabetismo, gestou um processo em que as prefeituras foram colocadas mais a serviço dos interesses dos capitalistas do sisal do que da maioria da população (SILVA, 2015, p.222).

No caso de Araci, a notícia fora debatida entre 5 leitores do site, dos quais 3 estavam a favor e 2 contra a 'ocupação do terreno da prefeitura'. Um desses leitores teceu um comentário que revela a perspectiva de surgimento de uma sociedade mais justa e humana:

0 brasil tem uma divida social a mais de 500 anos,e uma das piores é a de habitação,estas invasões de terra tanto urbana como rural é uma chaga aberta desde 1888 quando decretaram à abolição.Naquele momento deveria ter sido feito uma reforma agraria e urbana para assentar todos aqueles escravos que nada possuiam; só que foram todos jogados na sargeta e até hoje eles vivem desta forma. (Comentário do leitor. In.: CARVALHO, 2012).

Observa-se que o conflito atingiu outros agentes sociais e segue inaugurando no imaginário sertanejo, entre comentários contrários e a favor, o debate sobre a possibilidade de reelaboração da

\footnotetext{
${ }^{7}$ Sobre movimentos socioespaciais ver Fernandes $(2000 ; 2005)$. 
produção do espaço - a partir da luta pela redistribuição das terras urbanas - e da própria sociedade, em que os princípios humanos norteiem as decisões, considerando-se o fato de vivermos, conforme indica Touraine (2006), numa sociedade que é mais pensada e organizada em termos políticos do que social; observa-se que há uma espécie de 'consenso' (fruto dos pactos tácitos das elites hegemônicas explicitados por Sousa Santos, 2010) de que as pessoas devem trabalhar ou ter 'sorte na vida' para acessar por compra seus bens materiais - sem considerar as condições recebidas ou preexistentes -, sendo que existe grande dificuldade em reconhecer (especialmente entre pessoas com baixa escolaridade e pouca politização) o Estado como indutor de políticas públicas, de modo a responsabilizar e pressionar os gestores públicos a intervirem nos processos ampliados de produção de moradia, de financiamentos, atuando como reguladores de mercado e benfeitores sociais, ao invés de permitirem o laisse fairez, a autorregulação do mercado imobiliário e a especulação imobiliária.

Trata-se do predomínio da lógica do mercado em relação à lógica do direito relembradas por Porto-Gonçalves $(1998 ;$ 2010), que suplantou durante décadas formas públicas de provisão de moradia, embora após o governo Lula tenha havido forte investimento na construção de moradias através da criação do Fundo Nacional da Habitação e do Programa Minha Casa Minha Vida (PMCMV), que apesar de não ter conseguido atingir especialmente as famílias de até 03 salários mínimos - onde se concentra realmente o déficit - (FERREIRA, 2012), suavizou modicamente o grande déficit habitacional brasileiro, mas ampliou ainda mais a especulação imobiliária (SHIMBO, 2012).

Muitas são as distorções na efetivação do PMCMV, em diferentes escalas e, no âmbito das pequenas cidades baianas, especialmente no território sisaleiro, as grandes distorções provocaram fortes descontentamentos popular e mobilizações sociais que culminaram na ocupação das casas e protestos, por razões diversas.

Nos casos de Itiúba, São Domingos, Valente, Retirolândia, Conceição do Coité e Barrocas, as ocupações foram realizadas em casas do Programa Minha Casa Minha Vida. Os dados disponíveis não permitiram separar com exatidão se em todos os municípios onde houve ocupações dos imóveis, os ocupantes eram os futuros beneficiários ou se eram pessoas que não estavam cadastradas e reivindicavam o acesso à moradia.

O exame das entrevistas veiculadas evidencia que em muitos municípios as casas do Programa Minha Casa Minha Vida servem para a troca de votos, conforme se constata no relato do repórter Assis (2011):

\footnotetext{
"Isso é que dar", desabafou o aposentado Pedro Ferreira - Enquanto o prefeito autorizava um novo recadastramento, o aposentado Pedro Ferreira, 62 anos, morador na Fazenda Mandasaia, dizia na simplicidade do homem do campo: "Isto é que dar quando não se escolher direito". Disse isto e completou que ficou sabendo, assim que iniciou as inscrições, que o então prefeito Éwerton Rios, "Vetinho" teria distribuído as casas para os vereadores ratearem, e ele chegou a procurar quatros dos edis e todas disseram que já havia terminado suas cotas. (ASSIS, 2011).
} 
Em Quijingue, a mobilização social adquiriu um caráter essencialmente espacial a partir da decisão de interromper o tráfego na BA 381 como estratégia para pressionar os vereadores a votarem o projeto para a liberação da construção de 100 casas populares em Algodões (CORREIA, 2015).

Trata-se de mobilizações por direitos que lhes fora consagrado (cadastradas ou não, as pessoas foram finalmente informadas de que a moradia é um direito e o poder público deve promover o acesso de diferentes formas), mas cujo efetivo beneficiamento se prolonga infinitamente nos 'tempos' políticos que interessam às equipes das prefeituras, havendo a sensação de que a demora é maior para que a entrega do bem (aqui transformado em favor político), se dê o mais próximo possível das eleições, na busca do voto de agradecimento, num claro predomínio de uma lógica do favor, análoga à estratégia dos grupos hegemônicos chamada por Modesto (2013) de velhas práticas de reserva de carência (um por fazer), com vistas à manutenção do vínculo baseado na necessidade, cujas medidas paliativas adotadas pelos partidos políticos no poder público, asseguram a constância da 'doença' e não da 'cura'.

\section{CONCLUSÃo}

Os resultados encontrados expõem que há conflitos e luta por habitação mesmo nas menores cidades da Bahia, embora a escala política de sua ação muitas vezes não chegue a atingir sequer o próprio município onde ocorrem as mobilizações, mas dignas de noticiamento em blogs e sites de cobertura regional.

É evidente que é necessário analisar de modo aprofundado os desdobramentos desses conflitos, o teor dessas notícias, os juízos de valor aí imbuídos, mas o fato de que a ação repercute já é, em si, uma das vitórias da mobilização realizada: visibilidade e registro histórico.

Não há correlação direta entre o contingente populacional da população da sede, da densidade demográfica e grau de urbanização do município, com a existência ou inexistência de mobilizações sociais relacionadas à luta por habitação no território do sisal.

Há conflitos relacionados à moradia em nove dos vinte municípios do território do sisal. Muito genericamente, pode-se concluir que parece haver maior grau de politização e disposição para a luta por habitação, da população das cidades polarizadas por Conceição do Coité e Valente, do que da população das cidades polarizadas por Serrinha nesse início de século XXI.

Em Itiúba, São Domingos, Valente, Retirolândia, Conceição do Coité e Barrocas, ocorreram diferentes mobilizações sociais na luta pela moradia já consolidada, a partir de ocupações de unidades habitacionais do Programa Minha Casa Minha Vida, que podem ser consideradas de cunho socioterritorial, assim como as ocupações de terrenos privados e municipais em Santaluz e Araci, que além de recorrerem à ocupação direta, estão mais relacionadas ao questionamento da propriedade 
privada e da busca pelo valor de uso do solo urbano. Em Quijingue, a mobilização social pode ser considerada de caráter socioespacial, uma vez que recorre à interdição de via de tráfego para pressionar a aprovação de lei na câmara de vereadores.

Não foram encontrados movimentos sociais de luta por habitação no território do sisal, mas as mobilizações sociais identificadas denunciam que a cidade pequena não é o lugar onde nada acontece, como se quer fazer crer! Pelo contrário, a cidade pequena é o lugar onde mecanismos de controle social herdados de uma sociedade paternalista, elitista e segregadora, apresentam-se com muita força para gestar o imaginário de que nada acontece.

Conclui-se que, embora não tenham sido encontrados movimentos de luta por habitação popular, em cidades muito pequenas do semiárido sisaleiro baiano, os conflitos sociais por habitação denotam que outras forças estão sendo engendradas, há insurgências importantes, há articulações espontâneas e muito corajosas que podem gestar outros imaginários e novas ordens: há luta e esperança de que essa sociedade pode ser mais justa também nas pequenas cidades da Bahia!

\section{REFERÊNCIAS}

ALBUQUERQUE JR, D. M. de. A invenção do Nordeste e outras artes. Recife/SãoPaulo: Cortez, 1999.

ALMEIDA, A. P. Sociabilidade, cotidiano e vizinhança em um bairro popular de João Pessoa/PB. RBSE. 10 (29). P. 338-353. Agosto de 2011. Disponível em: <http://www.cchla. ufpb.br rbse/Index.html>. ARAUJO, O. Movimentos sócio-territoriais urbanos: a resistência dos sem-teto do 'Quilombo Lucas da Feira' (Feira de Santana - Bahia - Brasil). Revista Movimentos Sociais e Dinâmicas Espaciais, Recife, V. 06, N. 01, 2017. P.35-57.

ARAUJO DA SILVA, O. A territorialidade dos movimentos sociais urbanos: a luta pela habitação popular no Estado da Bahia. Santiago de Compostela: Universidade de Santiago de Compostela (tese de doutorado em Geografia), 2018. 333p.

ASSIS, V. de. Moradores deixam casas e passam a morar em barraco no Distrito de Valilândia. Domingo, 8 de janeiro de 2012. Atualização 09/01/2012. Disponível em:

http://goo.gl/oQXZRr. Acesso em 25 de abr. de 2016.

ASSIS, V. de. Sem tetos invadem casas do conjunto habitacional Casulo e prefeito ouve suas queixas. 4 de abril de 2011. Atualização 15/04/2011. Disponível em: http://goo.gl/p76Fcr. Acesso em 26 de abr. de 2016.
ASSIS, V. de. Sem tetos invadem terrenos na área urbana de Santaluz e paralisam rodovia. Terçafeira, 2 de julho de 2013. Atualização 03/07/2013. Disponível em: goo.gl/ivPAZ1. Acesso em 19 de abr. de 2016.

BOMFIM, J. D. Críticas práticas aos velhos \& novos movimentos sociais urbanos no Brasil. HUMANAS. Feira de Santana: UEFS. № 4. Jan./ jun., 2002. P. 83-108.

BOULOS, G. Por que ocupamos?: uma introdução à luta dos sem-teto. $3^{\text {a }}$ ed. São Paulo: Autonomia Literária, 2015. 125p.

BRASIL [2001]. Estatuto da cidade: Lei n. 10.257, de 10 julho de 2001, e legislação correlata. 2. ed. Brasília: Câmara dos Deputados, Edições Câmara, 2009. 69 p. Disponível em: http://bd.camara.gov.br/bd/ . Acesso em 10 de fev. de 2015.

CALILA NOTÍCIAS. Cansadas de esperar, dezenas de famílias invadem casas populares em São Domingos. 17 de setembro de 2015. Atualização 19/09/2015. Disponível em: http://goo.gl/KnQxs2. Acesso em 26 de abr. de 2016.

CARVALHO, Do K. Sem teto invadem terreno da prefeitura de Araci. Quarta-feira, 25 de janeiro de 2012. Atualização 27/01/2012. Disponível em: http://goo.gl/sCosVJ. Acesso em 25 de abr. de 2016. CASTRO, I. E. de. $O$ mito da necessidade: Discurso e prática do regionalismo nordestino. Rio de Janeiro: Bertrand Brasil, 1992. 
CORREIA, J. Manifestantes fecham BA 381 mais uma vez. 25/03/2015. Disponível em:

http://goo.gl/xvkST. Acesso em 26 de abr. de 2016.

DENALDI, R; CAMARU, F. de A. e GONÇALVES, L. F. Utilização do Sistema de Informação de Atenção Básica (SIAB) para identificar a precariedade habitacional no território dos pequenos municípios do Estado da Bahia, Brasil. 2014. P. 223 - 234.

FERNANDES, B. M. Movimento social como categoria geográfica. Terra Livre. São Paulo, n.15, 2000. P.59-85.

FERNANDES, B. M. Movimentos socioterritoriais e movimentos socioespaciais: contribuição teórica para uma leitura geográfica dos movimentos sociais. Revista NERA. Ano 8 no 6 . Presidente Prudente; jan/jun, 2005. P. 24-34.

FIRME-VIEIRA, A. J. A estratégia de "desenvolvimento territorial rural" no Rio de Janeiro: limites e oportunidades para grupos subalternos. UFF/ Niterói, 2011.178p. (tese de doutorado).

FERREIRA, R. F. Movimentos sociais, autogestão e a construção da política nacional de habitação no Brasil. In.: LAGO, L. C. do. Autogestão habitacional no Brasil: utopias e contradições. Rio de Janeiro: Letra Capital/ Observatório das Metrópoles, 2012. P. 116-138.

FONSECA, A. A. M da. A Geografia Política e a Valorização das Dinâmicas Locais. HUMANAS. Feira de Santana: UEFS. № 4. Jul./ dez., 2003. P. 11 $-37$.

FUNDAÇÃO JOÃO PINHEIRO. Déficit habitacional no Brasil 2013: resultados preliminares. Belo Horizonte, 2015. 13 p.

FRANK, A. G. e FONTES, M. Dez teses acerca dos movimentos sociais. Lua Nova. N. 17. São Paulo, junho de 1989. P. 19-48.

GIL, A. C. Métodos e técnicas de pesquisa social. 6⿳a ed. São Paulo: Atlas, 2011. 200p.

GOHN, M. da G. Teorias dos movimentos sociais: paradigmas clássicos e contemporâneos. $8^{\mathrm{a}} \mathrm{Ed}$. São Paulo: Loyola, 2010. 391p.

GORDILHO SOUZA, A. Limites do habitar: segregação e exclusão na configuração urbana contemporânea de Salvador e perspectivas no final do século XX. 2 a ed. Salvador: EDUFBA, 2008.

HAESBAERT, R. O Mito da Desterritorialização: do “Fim dos Territórios" à Multiterritorialidade. 5a ed. Rio de Janeiro: Bertrand Brasil, 2010.

IZAGUIRRE, I. Algunos ejes teóricos-metodológicos en el estudio del conflicto social. Movimientos sociales y conflictos en América Latina. In.: SEOANE, José. CLACSO, Consejo Latinoamericano de Ciencias Sociales. Buenos Aires, Argentina. Programa OSAL. 2003. 288 p. ISBN: 950-9231-924. Disponível em: http://goo.gl/OZoupI. JORGE QUIXABEIRA.COM. Itiúba: Ex vice-prefeito lidera invasão de casas do projeto Minha Casa
Minha Vida. 06 de abril de 2013. Disponível em: http://goo.gl/5MzXsr. Acesso em 26 de abr. de 2016.

LACOSTE, Y. A pesquisa e o trabalho de campo: um problema político para os pesquisadores, estudantes e cidadãos. Boletim Paulista de Geografia. no 84, 2006 [1977]. p. 77 - 92.

LOPES, D. M. F. Cidades pequenas do Semiárido: dinâmicas sociodemográficas e marginalização. In: LOPES, D. M. F.; HENRIQUE, W. (Org.). Cidades médias e pequenas: teorias, conceitos e estudos de caso. Salvador: SEI, 2010. p. 77-92. (Série Estudos e Pesquisas, 87).

MARICATO, E. $O$ impasse da política urbana no Brasil. Petrópolis: Vozes, 2011. 219p.

MARTIN, J.-Y. A geograficidade dos movimentos socioespaciais. Caderno Prudentino de Geografia, Presidente Prudente (SP), n¹9/20, p.26-41, Nov, 1997.

MELLUCCI, A. Um objetivo para os movimentos sociais?. Lua Nova. N. 17. São Paulo, junho de 1989. P. 49-66.

MENEGAT, E. A periferia é o limite: notas sobre a crise do modelo ocidental de urbanização. Cadernos Metrópole, N. 13, pp. 107-132, 1ํ sem, 2005.

MODESTO, N. S. d'Á. Jogo político em São Gonçalo RJ: (re) produção espacial promovida pela ação dos grupos de poder hegemônico. In: CARLOS, A. F. A; SOUZA, M. L. de; SPOSITO, M. E. B. (orgs.). $A$ produção do espaço urbano: agentes e processos, escalas e desafios. São Paulo: Contexto, 2013. P. 41-51.

MONTAÑO, C. e DURIGUETTO, M. L. Estado, Classe e Movimento Social. 3a ed. São Paulo: Cortez, 2011. $384 \mathrm{p}$.

PEDON, N. R. Geografia e movimentos sociais: Dos primeiros estudos à abordagem socioterritorial. São Paulo: Editora UNESP, 2013. 250p.

PORTO-GONÇALVES, C. W. Geografia e movimentos sociais no processo de globalização em curso: apontamentos. Boletim Gaúcho de Geografia, 24, p. 19-30, maio, 1998.

RANGEL, L.; VILELA, J.; PORTO-GONÇALVES, C. W. Geo-grafando: os múltiplos protagonistas na América Latina em Transformação. s/d. Disponível em: http://goo.gl/b8acPw.

PORTO-GONÇALVES, C. W. A geograficidade do social: uma contribuição para o debate metodológico para os estudos de conflitos e movimentos sociais na América Latina. Revista Eletrônica da Associação dos Geógrafos Brasileiros - Seção Três Lagoas - MS, v.1 - № 3 - ANO 3, Maio de 2006.

PORTO-GONÇALVES, C. W. (2010). A reinvenção dos territórios: a experiência latino-americana e caribenha. In: COELHO NETO, A.; SANTOS, E. M. C.; SILVA, O. A. da (Orgs.). (Geo)grafias dos 
movimentos sociais. Feira de Santana: UEFS Editora. (p. 15 -170).

RUBEM, Rubenilson. Barrocas: Todas as 40 casas do Conjunto Habitacional Minha Casa Minha Vida 2 encontram-se ocupadas. SEXTA-FEIRA, 27 DE MARÇO DE 2015. Disponível em: http://goo.gl/ijihLX. Acesso em 25 de abr. de 2016.

SANTOS, E. M. C; SILVA, O.A.; ARAUJO, O. A precarização do trabalho rural no processo produtivo do sisal: a informalidade e o silêncio dos inocentes. Anais XI Jornada do trabalho. João Pessoa, 2010.

SANTOS, E. M. C. Associativismo e desenvolvimento: $o$ caso da Região Sisaleira da Bahia. Feira de Santana: UEFS Editora, 2010.

SANTOS, E. M. C.; SILVA, O. A. da.; COELHO NETO, A. S. Gente ajudando gente: o tecido associativista no Território do Sisal. Feira de Santana: UEFS Editora, 2011.

SANTOS, E. M. C.; SILVA, O. A. da.; COELHO NETO, A. S. De Região Sisaleira a Território do Sisal: desvelando as nuances do processo de delimitação da diferenciação espacial no Semiárido Baiano. GeoTextos, vol. 11, n. 2, dezembro, 2015. P. 131-15. SANTOS, J. Urbanização e produção de cidades na Bahia: reflexões sobre os processos de estruturação e reestruturação urbana. BAHIA Análise \& Dados, Salvador, v. 19, n. 2, p. 499-509, jul./set, 2009.

SANTOS, M. A urbanização brasileira. 5a ed. São Paulo: EDUSP, 2009 [1993]. 174p.

SANTOS, R. E. dos. Movimentos sociais e Geografia: sobre a espacialidade da ação social. Rio de Janeiro: Consequência, 2011. 350p.

SHIMBO, L. Z. Habitação social de mercado: A confluência entre Estado, empresas construtoras e capital financeiro. Belo Horizonte: C/Arte, 2012. $222 p$.

SILVA, B.-C. N. e ROCHA, A. P. Análise da Dinâmica da Urbanização no Estado da Bahia - 1940/2000. In: SILVA, S. B. de M. e SILVA, B.-C. N. Estudos sobre globalização, território e Bahia. Salvador: UFBA, 2003

SILVA, O. A. da. Rede urbana e dinâmica regional no estado da Bahia: um olhar sobre o território do sisal. In.: DIAS, P. C., BRANDÃO, P. R. B. (organizadores). Cidades médias e pequenas: dinâmicas espaciais, contradições e perspectivas na relação cidade-campo. Salvador: SEI, 2015. P. 215229.

SOUSA SANTOS, Boaventura de. A gramática do tempo: para uma nova cultura política. $4^{\mathrm{a}}$ ed. São Paulo: Cortez, 2010 [2006]. 511p.

SOUZA, M. L. de. A prisão e a ágora: reflexões em torno da democratização e do planejamento e da gestão das cidades. Rio de Janeiro: Bertrand Brasil, 2006.
SOUZA, M. L. de. Introdução: A “nova geração” de movimentos sociais urbanos - e a nova onda de interesse acadêmico pelo assunto. Revista CIDADES. Vol. 6, n.9. Presidente Prudente/ SP: Grupo de Estudos Urbanos/ Expressão Popular, 2009. P. 9-26.

TOMIMURA, P. e MUNIZ, H. P. Ocupações do Movimento dos Sem-teto e a Psicologia do Trabalho. Psicologia \& Sociedade, 24(2), 2012. P. 453-461.

TOURAINE, A. Na fronteira dos movimentos sociais. Sociedade e Estado. Brasília, v. 21, n. 1, p. 17-28, jan./abr. 2006.

VÁZQUEZ, M. I. Teoría en movimiento: Más de una década de pensamiento crítico. OSAL (Observatorio Social de América Latina). Buenos Aires: CLACSO, Año XII, N³0, noviembre, 2011. P. $25-42$. 